\title{
OS NOVOS RUMOS DA HISTÓRIA ORAL: O CASO BRASILEIRO
}

\author{
José Carlos Sebe Bom Meihy
}

Coordenador do Núcleo de Estudos em História Oral - USP

\section{Resumo}

A História Oral tem sido objeto de muitas discussões nos dias de hoje.É consensual, entretanto, que a história oral atingiu sua maioridade, e que apesar da discussão necessária, sobre o seu status, cada vez mais encontramos pessoas interessadas no tema. Nos processos de mudança no campo da história oral, é inegável o empenho com que seus estudiosos têm se empenhado em divulgá-la.

\section{Pallavras-Chave}

História Oral • Futuro • Brasil • Rumos • Estudos.

\section{Abstract}

The Oral History has been subject of many discussions nowadays. It is common sense that Oral History has already reached its adulthood, and in spite of the necessary discussion, about its status, we can find many people interested on the subject. On the Oral History chancing process, it is undeniable the determination of the Oral History's studious who has been determined to spread it. This article discuss about the Oral History future in Brazil.

\section{Keywords}

Oral History $\bullet$ Future $\bullet$ Brazil $\bullet$ Direction $\bullet$ Studies 


\section{Apresentação}

De certa forma, parece irônico definir como "novos" os "rumos da história oral". Esta constatação maliciosa equivale a um juízo que compromete a existência da história oral como entidade teórica e definida que já percorreu um caminho que, depois de filtrado por críticas, busca, com base no suposto passado, orientações para o próprio futuro. Mesmo antes de entrar no âmbito da proposta, cabe recortar o espaço da história oral brasileira salientando a originalidade de seu surgimento e as características básicas de seu desenvolvimento desde a abertura política no alvorecer dos anos de $1980 .{ }^{1}$ Nesta linha, vale lembrar que um dos temas mais recorrentes da reflexão sobre o contexto da história oral brasileira é a constante prática de avaliação. ${ }^{2}$ De modo geral, ressalto três situações que marcam nossa prática neste campo:

1 - O fato dos primeiros textos sobre esta proposta terem nascido no exílio;

2 - O estigma colonizado de nossos textos que, fatalmente, buscam legitimidade em debates exóticos, estrangeiros e alheios ao nosso meio;

3 - A carência de trabalhos de fôlego que extraiam a prática de nossa história oral dos pequenos artigos, coletâneas ou falas exclusivamente teóricas onde, no máximo, a base empírica é usada como exemplo. ${ }^{3}$

Porque se duvida da existência de conceitos estabelecidos sobre o que seja a história oral no meio brasileiro, supõe-se que antes da busca dos tais "novos rumos", faz-se necessário o entendimento das "antigas rotas" que conduziram a reflexão do atual momento que se clama "redefinidor de rumos". Antes, vale qualificar o lugar de onde se fala. Por estarmos no espaço da academia, por assumirmos posições estabelecidas no Brasil, temos que conformar nossa apre-

\footnotetext{
${ }^{1}$ A história oral brasileira, como a do resto da América Latina, esteve sujeita à circunstância da abertura política nacional. Esta marca, aliás, garante o caráter democrático que marca a história oral.

${ }^{2}$ Há um número exageradamente grande de textos que remontam à fase de criação da história oral no Brasil.

${ }^{3}$ Anteriormente, sobre este tema publiquei: "Oral History in Brazil: Development and Challenges. Oral History Review”, California, Estados Unidos, v. 26, p. 127-136, 1999.
} 
sentação a partir de visões que comprometam o exame de um modelo de produção acadêmica do saber e, sobretudo, supor os limites de um exercício analítico feito na universidade brasileira. ${ }^{4}$ Assim, formula-se um primeiro ponto para que pensemos nos "rumos" - "novos"? - da história oral entre nós. A problematização da proposta indicativa do "futuro da história oral no Brasil", portanto, depende muito do cruzamento de dois fatores combinados:

1 - Do significado do saber universitário no Brasil e suas vinculações com a integração do saber na vivência da prática social e;

2 - Do eventual peso da história oral no conjunto curricular das matérias de humanidades em nossa academia.

Basta enunciar este "problema" para que tenhamos a dimensão do desajuste, da má colocação da história oral como alternativa respeitável de saber social. A negação peremptória do conhecimento como base da formulação de políticas públicas, inviabiliza nexos que, de regra, são tidos como "outra coisa". Aplicando este princípio à história oral, nota-se que o desdobramento desta problemática pode elucidar a validade de não definições que, em última análise, são úteis para a formulação de um saber descompromissado, de funções sociais sempre indecisas na cultura universitária brasileira. Assim, o polêmico dilema da história oral brasileira - o fato de ser uma proposta de amplíssima aceitação em nosso meio social e a sua pífia definição conceitual - recoloca a validade de não defini-la além de um instrumento aplicável seja à antropologia, história, psicologia, sociologia, geografia humana, jornalismo. Dela, aliás, já se afirmou ser uma "terra de ninguém" e por isto "lugar de vale tudo". Como "ferramenta", "técnica", "metodologia" ou meramente "saber", nossa história oral é sempre um apoio, jamais matéria independente. Assim, questões como memória e identidade, fundamentos dos estudos com base em história oral, passam a ser sempre

\footnotetext{
${ }^{4}$ É fundamental que seja considerado o ambiente brasileiro como contextualizador de um tipo de história oral. Sem levar em conta que temos uma circunstância específica que talha o tipo de história oral que praticamos pode-se perder a noção de sua finalidade como recurso novo. Portanto, parte-se do pressuposto fundamental de que história oral não é apenas entrevista ou produção de documentos.
} 
apêndices de outros recursos disciplinares e jamais ganham autonomia como essência do "tempo presente". Da mesma forma, discussão sobre o estatuto da história oral padece de isolamento, pois, com segurança, o cruzamento entre propostas de "história do tempo presente" aliadas a história oral poderiam comprometer os alicerces das "ciências humanas" criadas no século XIX.

Dizendo de outra forma, é exatamente porque segundo uma postura tradicional de feições exclusivamente culturalistas que se vê consagrada a noção de história oral como mais um recurso de conhecimento. Se, contudo, diversamente buscarmos o sentido social do conhecimento, chegaremos a uma postura, política e até militante, que vê a história oral como um recurso de transformação e não apenas de acesso ao conhecimento ou informação. É evidente que a busca do conhecimento e informação como meio de transformação é o objetivo do que estou convencionando chamar de história oral, mas, como fim, não como meio.

\section{História Oral como divisão de saberes}

Criou-se uma linha divisória capaz de separar dois campos abertos à definição de história oral: de um lado a vertente culturalista, de outro a instrumental. Para respostas adequadas sobre o tema temos de qualificar as questões essenciais a seu entendimento: Por que história oral? De quem? Para quem? De um lado situam-se posturas bem formuladas que se aprazem em repetir de jeitos novos, soluções antigas e - por que não dizer? - alienadas, de formulação de conteúdos acadêmicos gastos e sem função social, pois afinal como já se disse ad nauseam "a história oral não é solução para tudo". Avesso desta postura, um saber ativista e que propõe remodelações no papel da produção acadêmica excita a imaginação daqueles que vêem mais uma dimensão nos deveres universitários de pensar a sociedade: a contribuição para políticas públicas instruídas. Ainda que seja aceito o inevitável - que história oral não seja solução para tudo - sabe-se que ela é, pelo menos, uma janela que deixa ventilar o ar puro do "tempo presente" e que sem ele não se pode pensar a sociedade e os projetos de melhoria da vida coletiva com base em saber rigoroso e comprometido.

Evocando lições que desdobram desde Hegel, passando por Dilthey, Walter Benjamin, Lucien Goldmann, temos a noção diferenciada entre "verdade" e "experiência" ou dizendo de outra maneira entre "realidade" e "vivência". Assim, o consagrado axioma "compreender para explicar" ganha mais uma dimensão ao ser aliado à "transformação". Então, construindo um novo silogismo temos que: compreendendo para explicar, explicamos para transformar, 
donde "compreender é transformar". Transformação, portanto, passa a ser o objetivo da história oral. ${ }^{5}$ Não se fala, contudo de uma transformação em sentido plano, restrito, simples, meramente imediato. Toda a ação da história oral é transformadora. E isto em todos os níveis, desde a elaboração do projeto, escolha dos colaboradores, operação de entrevista, produção textual e eventual análise. Durante todas as fases de execução da história oral temos um compromisso com a transformação sem o que a história oral não tem razão de ser. Sem isso, aliás, não se tem história oral e sim o velho e consagrado uso de entrevistas de cunho testemunhal.

A novidade aqui proposta se efetiva na superação do limite culturalista. Porque se credita ao saber universitário, acadêmico, mais do que compreender, assume-se o compromisso com o social como princípio, meio e fim da história oral. O destino transformador, portanto, é a marca de honra da história oral.

\section{História Oral instrumental}

Sem abdicar o caráter instruído, criterioso e feito com rigor, do saber feito na universidade, evocam-se os motivos da história oral. Nada melhor para sustentar os fins da história oral do que partir de reflexões sobre a motivação para sua prática. Segundo Philippe Joutard, há, originalmente, três motivos que impulsionam o fazer da história oral:

1 - Escuchar la voz de los excluidos;

2 - Sacar a la luz las realidades 'indescriptibles';

3 - Dar testimonios de las situaciones de sufrimiento extremo. ${ }^{6}$

Joutard não está sozinho na postura de comprometimento da história oral com a transformação da sociedade. Com diferentes vieses autores como Trebitsch e François, elegem o caráter oralístico de entrevistas como forma alternativa de proposta para uma história diversa da habitual feita sobre bases

\footnotetext{
${ }^{5}$ Alberto Lins Caldas desenvolveu a noção de transformação da natureza do saber centrandose no princípio da transcriação que seria mais do que a transformação do oral para o escrito e sim de todo processo de elaboração do projeto em história oral. Sobre o assunto leia-se: CALDAS, Alberto Lins. Nas águas do texto: palavra, experiência e leitura em História Oral. Porto Velho, 2001.

${ }^{6}$ JOUTARD, Philippe. "Nuevas Polémicas Sobre Historia Oral: algunos retos que se le plantean a la Historia Oral del Siglo XXI" in Historia,Antroplogia y Fuentes Orales, num. 21, 1999, p151.
} 
documentais "tradicionais". ${ }^{7} \mathrm{O}$ importante desta constatação é a especificidade dos fundamentos da história oral que, de raiz, seriam diferentes dos objetivos de qualquer outra disciplina das áreas de humanidades. Por esta indicação, não fica restrito à História - com "H" maiúsculo - o monopólio da história oral. Nem a qualquer outra área do conhecimento, diga-se. E isto coloca em tela de juízo a questão dos "novos rumos". E se história oral é algo novo, um dos primeiros compromissos de quem se propõe a ser oralista é se posicionar como tal, acima e sobre qualquer aposto disciplinar.

Por que se endossa a proposta de Joutard, pressupõe-se o enfrentamento do incômodo debate sobre o adjetivo "oral" ao sujeito "história" e, nesta senda, cabe notar que a apropriação dos historiadores deste recurso a submete a uma perversa utilização das narrativas orais à condição de "fonte". E, e, geral, os historiadores e demais acadêmicos das áreas das humanidades têm sido implacáveis na inclusão dos discursos orais como forma de alimento de objetivos culturalistas específicos que marcam a longa seqüência de trabalhos derivados da "Nova História" ou da "História Cultural". O império dos historiadores sobre as fontes orais, aliás, reproduz os maus tratos notados entre estes e os sociólogos, antropólogos e demais grupos useiros da oralidade como recurso para suas tarefas analíticas. Um exemplo eloqüente disto pode ser aferido pela postura autoritária de personagens fundamentais no mundo da história oral. Ao se referir a uma "História sem adjetivos", por exemplo, Mercedes Vilanova impõe uma prática única para o emprego das fontes orais: seu uso para a História que se elevaria sobre as demais disciplinas. ${ }^{8}$

Há dois novos argumentos a enriquecer a proposta da história oral como procedimento disciplinar independente e alheio às demais disciplinas estabelecidas ao longo do século XIX. Um, a noção derivada do axioma de que his-

\footnotetext{
${ }^{7}$ Sobre o assunto leia-se de Michel Treblisch: A função epistemológica e ideológica da história oral no discurso da história contemporânea e A fecundidade da história oral ambos in Marieta de Moraes Ferreira (org.) História oral e multidisciplinalidade. Rio de Janeiro, Diadorim/Finep, pp. 19-43 e 3-13, respectivamente.

${ }^{8}$ A luta por atualização da História enquanto uma disciplina tem levado muitos autores a filtrar o uso das entrevistas. Mercedes Vilanova, nesta direção, discute as virtudes de uma "História sem adjetivos" (oral, por exemplo) e propõem a atenção aos resultados e não aos meios documentais. Sobre o assunto leia-se o artigo desta autora in História, Antropologia y Fuente Oral, num. 14, Barcelona, Universitat de Barcelona, 1995, p. 95.
} 
tória oral é mais do que entrevista e nesta linha um processo de transformação de realidades; outro o caráter social que implica na qualificação do sujeito coletivo como motivo da História. A subversão do principio da História que viria do pretérito para o presente e a consagração do inverso - do presente para o passado - aliado a um novo protagonista da narrativa - o narrador - seria a base para uma relação que retraça fundamentos para o saber. Seria então matéria da história oral captar as vozes ocultas pelo saber oficializado, construído por meio de documentos convencionais, principalmente escritos. De igual importância seriam os aspectos insondáveis e principalmente o registro e a reparação de situações traumáticas. Retomando a proposta de Joutard, fala-se aqui de uma história oral instrumental por excelência. É curioso notar, nesta linha, que mesmo pessoas que tradicionalmente trabalham com o que chamam de história oral, na América Latina, acabam por promover visões que contradizem a prática que julgam válidas. Por exemplo, depois de definir que história oral é mais do que uma técnica, e que constitui em uma metodologia, uma das fundadoras da história oral latino-americana, Eugenia Meyer retoma um dos princípios germinais da matéria dizendo que "Asimismo y debido probablemente a la naturaleza de nuestras realidades latinoamericanas, las idas y venidas de 'caudillos', los golpes militares, las dictaduras y las constantes violaciones de los derechos humanos, el trabajo y el resultado de la historia oral adquiere uma dimensión fundamental, su caráter de denuncia". ${ }^{9}$ É este caráter "de denúncia" aliado a uma agenda fundamentada na busca de inclusão social que a um só tempo garantiria o aspecto democrático e social da história oral.

O uso da história oral, portanto deveria ser aplicado onde os documentos convencionais não atuam, revelando segredos, detalhes, ângulos pouco ou nada prezados pelos documentos formalizados em códigos dignificados por um saber acadêmico que se definiu longe das políticas públicas. Aspectos subjetivos, deformações dos fatos, mentiras, fantasias, ilusões, seriam, pois elementos consideráveis para quem procura mais do que a "verdade" os motivos das "inverdades". Sem a consideração dos fatores ocultos, das lacunas e das

\footnotetext{
${ }^{9}$ Meyer, Eugenia. Recuperando, Recordando, Denuciando, Custodiano la Memoria del Pasado Puesto al Día. Historia Oral en Latinoamérica y el Caribe in: Historia y Fuente Oral, num.5, 1991, p.140.
} 
subjetividades é inviável se pensar na história oral que superaria, por gênese, os documentos convencionalmente consagrados como "históricos".

Falar de funções instrumentais da história oral, extrair esta discussão do pântano confuso que a limita a uma ação "de apoio" à História ou a outras disciplinas humanísticas implica extrair o debate da simplificação que vê, por exemplo, duas falhas na negociação de uma história oral como moeda militante: de um lado a história oral como missão, e, de outro, a história oral como instrumento para fazer a História.

\section{História Oral, o Missionário e o Cidadão}

É pobre e vulgar delegar a pecha de "missionária" a uma proposta de história oral que vise à inclusão social em vez de facilitadora de explicações culturalistas.

Pobre porque quando se pensa na formulação de argumentos que atuam na composição de um texto de história oral, quase sempre, ainda predominam os pressupostos definidos por Michael Pollak quando estabeleceu as "memórias em disputa". ${ }^{10}$ A proposta de Pollak parte da relativização da hegemonia de memórias que se sobrepõem uma à outra até a oficialização. O emprego dessa visão, contudo, merece uma visita remodeladora. Quando se propõe uma prática onde em vez de hierarquizar as memórias as paralelizam de maneira a mostrar em um mesmo grupo oposições formula-se um espaço de debate tem-se que mais de uma unidade, pode-se ver a divisão em redes que abrigam na identidade, diferenças. Então, formular outras relações que possam em vez de "verticalizar" as forças de dominação de memórias, "horizontalizá-las" é mais do que ver "memórias dominantes" ou "memórias dominadas". Assim, no lugar de assinalar que uma memória como dos gaullistas da Resistência na Segunda Guerra foi dominada pelos nazistas e que, contudo, em vista dos comunistas passa a ser dominadora posto que estes foram vencidos, pode resultar em um diálogo. O grande mérito desta proposta é ressaltar o confronto e as lutas internas a grupos que constroem a própria memória como forma de estabelecer o seu lugar no espaço democrático. Com isto garante-se que mais do que a busca de uma explicação, a história oral ao admitir outras vozes em um mesmo projeto releva o

\footnotetext{
${ }^{10}$ POLLAK, Michael. "Memória, esquecimento, silêncio". In: Estudos Históricos. Rio de Janeiro, CPDOC-FGV, v. 2, n.3, 1989, p. 4.
} 
papel das lógicas que se opõem. Desta forma, não se pode pensar, por exemplo, em entender um processo como um todo se não forem levados em consideração os discursos opostos: não há história oral dos torturados sem a consideração dos argumentos do torturados. Vítimas e perpetradores dividem um mesmo espaço histórico que só se explica em conjunto.

Vulgar porque mais que encaixar o "depoimento" como uma forma de enquadramento da memória, garante-lhe força capaz de anular a noção de dominância e estabelecer uma dignidade de aspectos de construções identitárias dos grupos. É o diálogo que passa a interessar e os conflitos internos de cada grupo em vez de cristalizar os argumentos propostos por cada causa, passam a expressar a luta de cada camada.

Afinal, porque não se percebe nos projetos de uma história oral militante o papel de juiz, e sim de mediador de causas, não se verifica a posição de memórias concorrentes e sim de argumentos que se opõem em busca de um diálogo. Daí o caráter cidadão da história oral. E também de respeito às partes.

É lógico que não se confunde a fonte oral com a História e neste sentido o debate formulado no jogo de palavras que confunde "fazer a história com o fazer História". A este propósito, aliás, vale recortar a parcela da conclusão definida por Verena Alberti ao dizer que:

mas a possibilidade de realizar entrevistas de história oral com pessoas de grupos sociais distintos não exime o pesquisador da interpretação e da análise do material colhido. Falar de história democrática pode levar ao equivoco de se tomar a própria entrevista não como fonte - a ser trabalhada, analisada e comparada a outras fontes - e sim como história. ${ }^{11}$

Como o objetivo proposto na busca de um rumo para a história oral brasileira é a formulação de argumentos para políticas públicas, e por não entender que a história oral seja apenas uma alavanca "a mais" para ser "trabalhada, analisada e comparada a outras fontes" percebe-se que sim, que no compromisso de registrar, estabelecer texto em conjunto com o colaborador e defini-lo como

\footnotetext{
${ }^{11}$ ALBERTI, Verena. "História oral e terapia: o exemplo alemão". In: Ouvir Contar: textos em história Oral. Rio de Janeiro: FGV Editora, 2004, p. 46.
} 
memória de uma "rede" compreendida no circuito de colônias que se definem em uma "comunidade de destino" está o cerne da historicidade das narrativas.

\section{Mas quais são os "novos rumos" para a História Oral?}

Incertos. Assim como não são definidas as origens da história oral produzida no Brasil, são incertos os rumos futuros da história oral brasileira. ${ }^{12}$ Nem poderia ser de outra forma, pois ainda não alçamos a formulação de problemas centrais da "nossa" história oral. Da mesma forma, carecem ainda de fundamentos as apropriações da oralidade nas diferentes disciplinas acadêmicas. Isto sem falar da quase leviandade em se aplicar ao uso de entrevistas à conceituação de história oral.

Mas há também boas promessas. Seja pela adesão exemplar de pessoas que ligam nos debates, seja pela possibilidade de um alargamento mais expressivo do uso da palavra como forma de inclusão social ou mesmo pela pressão externa terá que definir os terrenos produtores de trabalhos sobre história oral. Nesta linha, aliás, cabe ressaltar o papel das novas gerações que - estas sim -, sem serem xenófobas, passam a fazer pesquisas de campo e se mantém razoavelmente alheias às práticas "dependentistas" de legitimação dos próprios trabalhos segundo inspiração estrangeira.

Então, conclui-se que os novos rumos da história oral brasileira dependem das orientações assumidas pelos pesquisadores das gerações ora em formação e da crítica que deve decorrer de novos balanços da produção existentes agora executados sob a luz de alternativas mais ágeis, modernas, menos defensivas ou retrogradas. O que se espera no futuro? Pelo menos mais trabalhos empíricos e agressividade nos resultados que, por fim, devem remeter à política. Na melhor das esperanças, almeja-se que a história oral seja menos um fator de alienação e mais de transformação.

\footnotetext{
${ }^{12}$ Em debate anterior discuti as possibilidades de formação de uma agenda para o estabelecimento de uma história oral latino-americana. Sobre o assunto, leia-se MEIHY, J. C. S. B. Desafios da História Oral Latino-Americana: o caso do Brasil. In: FERREIRA, Marieta de Moraes; FERNANDES, Tania Maria; ALBERTI, Verena (Org.). História Oral: Desafios para o século XXI. Rio de Janeiro: Editora Fiocruz, 2000, v. , p. 85-97.
} 


\section{Bibliografia}

\section{Manuais e obras de referência geral}

ALBERTI, V. História oral: a experiência do CPDOC. Rio de Janeiro: Instituto de Documentação, Editora da Fundação Getúlio Vargas, 1990.

CORREIA, C.H.P.. História Oral: teoria e técnica. Florianópolis: Ed. Univ. Federal de Santa Catarina, 1978.

JOUTARD, P.. Esas voces que nos llegan del passado. México: Fondo de Cultura Económica, 1986.

LANG, A.B.S.G. et al. . História oral e pesquisa sociológica : a experiência do CERU. São Paulo: Humanitas, 1998.

MEIHY, J.C.S.B.. Manual de história oral . $5^{\mathrm{a}}$ ed. São Paulo: Loyola, 2005.

THOMPSON, P.. A voz do passado . $2^{\mathrm{a}}$ ed. Rio de Janeiro: Paz \& Terra, 1992

\section{Coletâneas de artigos e anais de congressos}

FERREIRA, M.M (org.). História oral e multidisciplinaridade. Rio de Janeiro: Diadorim, 1994.

FERREIRA, M.M et al. Entre-vistas :abordagens e usos da história oral . Rio de Janeiro: Editora da Fundação Getúlio Vargas, 1994.

MEIHY, J.C.S.B. (org.). (Re)introduzindo a historia oral no brasil :1. encontro regional de historia oral . São Paulo: FFLCH/Xamã, 1996

MEIHY, J.C.S.B. (org.).Projeto História , "Ética e História Oral”, n.15, Abr/97

\section{Revistas especializadas}

História, Antropología y Fuentes Orales, Espanha

História Oral . Associação Brasileira de Histórial Oral, Brasil

NEHO-História, Núcleo de Estudos em História Oral, Brasil

Oral History Review, Oral Histrory Association, EUA

Oral History, Oral History Society, Inglaterra 
Voces Recobradas . Argentina.

Words and Silences (versão espanhola - Palabras e Silencios ), International Oral History Association.

\section{Balanços historiográficos}

ALBERTI, V. “Obras coletivas de história oral”, Tempo, vol. 2, n. 3, Jun/97, pp. 206-219

FERREIRA, M. "Desafios e dilemas da história oral nos anos 90: o caso do Brasil", História Oral, n.1, Jun/98, pp. 19-30.

GATTAZ, A. "Meio século de história oral”, Neho-história, n.0, Jun/98, pp. 21-33. História, Antropología y Fuentes Orales. (até o n. 13: História y Fuente Oral) Barcelona.

JOUTARD, P. "História oral: balanço da metodologia e da produção nos últimos 25 anos", in: FERREIRA, M. \& AMADO, J. (org.). Usos e abusos da história oral. Rio de Janeiro, FGV, 1996, pp.43-64.

\section{Algumas obras temáticas}

BOSI, E.. Memória e sociedade. Lembranças de velhos . $3^{\mathrm{a}}$ ed. São Paulo: Cia. das Letras, 1995.

GATAZ, A.C. Braços da resistência, uma história oral da imigração espanhola. São Paulo: Xamã, 1996

LIMA, V.R. (coord.) Getúlio: uma história oral. Rio de Janeiro: Editora Record, 1986.

MEIHY, J.C.S.B. A colônia brasilianista. História oral de vida acadêmica. São Paulo, Nova Stella, 1990.

MEIHY, J.C.S.B. Canto de morte Kaiowaá. História oral de vida. São Paulo: Loyola, 1991.

MONTENEGRO, A. T. História oral e memória: a cultura popular revisitada. São Paulo: Editora Contexto, 1992.

NADER, A.B. Autênticos do MDB, semeadores da democracia :história oral de vida política. São Paulo: Paz e Terra, 1998. 
PATAI, D. Brazilian Women Speak. EUA, Rutgers University Press: New Brunswick, 1988.

SANTOS, A.P. Ponto de vida. Cidadania de mulheres faveladas. São Paulo: Loyola, 1996.

VILANOVA, M. Mayorías invesibles, Barcelona, Icaria, s/d. 